\title{
APOLLONII ALEXANDRINI
}

\section{DE CONSTRUCTIONE}

ORATIONIS

L I B I Q UATUOR

EX RECENSIONE

I M M ANUELIS BEKKERI.

B E R O L I N I.

IMIPENSIS GE. REIMERI.

$18 \times 7$. 

MAXIMILIANO SEGUERIO

\author{
BELLO VACO
}

HOSPITI SUO ET AMICO

$$
\text { D. }
$$

EDITOR. 
